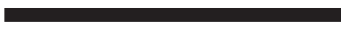

AUTORAS:

Rita Silva ${ }^{1}$

Paula Queirós ${ }^{1}$

Isabel Mesquita ${ }^{1}$ ber da experiência. Rev. Bras. Educ. 19: 20-28.

2. Nascimento JV, Ramos V, Marcon D, Saad MA, Collet C (2009). Formação acadêmica e intervenção pedagógica nos esportes. Mortiz, 15 (2): 358-366.

3. Clemente FM (2012). Princípios Pedagógicos do 13. Ramos V, Souza JRS, Brasil VZ, Barros TES, NasTeaching Games for Understanding e da Pedagogia cimento JV (2014). As crenças sobre o ensino dos Não-Linear no ensino da Educação Física. Movimento esporres na formação inicial em Educação Física. Ver. 18 (2): 315-335.

Educ. Fis/UEM, 25 (2): 231-244.

(2014). Uma visão integrada do mo-

delo Teaching Games for Understanding: adequando os

estilos de ensino e questionamento à realidade da Edu-

cação Física. Rev. Bras. Ciênc. Esporte 36 (2): 587-601.

5. Coutinho NF, Silva, SAPS (2009). Conhecimento e

aplicação de métodos de ensino ara os jogos esporti-

vos coletivos na formação profissional em Educação

Física. Movimento 15 (1): 117-144.

6. Formosinho J (2009). A formação prática dos pro-

fessores: da prática docente na instituição de forma-

ção à prática pedagógica nas escolas. In. Formosinho

J (ed.) Formação de professores - aprendizagem profissionat accão docente Porto Po to Editora $93-117$.

7. Griffin LL Patton K (2005). Two decades of Teach-

ing Games for Understanding: looking at the past, pre-

sente and future. In: Griffin LL, Butler JL (ed.) Teach-

ing Games for Understanding: theory, research and

practice. Champaing: Human Kinetics, 1-18.

8. Howarth K. (2005). Introducing the Teaching

Games for Understanding model in teacher educa-

tion programs. In: Griffin LL. Butler H (ed) Teaching

In: Grifin

tice. Champaing: Human Kinetics, 91-105.

9. Marcon D, Graça A, Nascimento JV (2011). Con-

siderações teóricas sobre o conhecimento pedagó-

gico do conteúdo na formaçấo inicial em Educação

Física. Rev Port Cien Desp, 11 (3): 127-139,

10. Memmert D, Almond L, Bunker D, Butler J, Fasold

F, Griffin L, Hilmann W, Hüttermann S, Klein-Sotebier

T. König S, NoOp S, Rasthchlag M, Schul K, SchWD S

Thorpe R, Furley F (2015). Top 10 research questions

related to Teaching Games for Understanding. Res Q Exerc Sport 0 (0): 1-13

11. Mosston M, Ashwoth S (2008). Teaching Phys-

ical Education (First online edition). Disponível em <

http://www.spectrumofteachingstyles.org/e-book-

-download.php>. Acesso em 10

FADEUP. Faculdade de Desporto da Universidade do Porto, Portugal

https://doi.org/10.5628/rpcd.17.S1A.107
Modelos de Ensino

do Desporto: 0 olhar

dos alunos. Estudo no âmbito

do Estágio Profissional

em Educação Física

PALAVRAS CHAVE:

Modelos de Ensino. Educação Física.

Estágio Profissional.

\title{
RESUMO
}

O presente estudo examinou a representação de alunos, sobre as vivências em aulas de Educação Física, nas quais foram usados modelos de ensino centrados no professor (Modelo de Instrução Direta) e modelos de ensino centrados nos alunos (Ensino por Pares, Aprendizagem Cooperativa e Educação Desportiva). Participou no estudo uma professora estagiária e vinte e cinco alunos (13 do sexo feminino e 12 do sexo masculino) do $10^{\circ}$ ano de escolaridade. A recolha de dados foi realizada através de entrevistas de grupo focais de natureza semiestruturada. Recorreu-se à análise temática e a procedimentos indutivos para construir uma compreensão aprofundada sobre o fenómeno investigado. Este estudo reforça a importância da aplicação de modelos de ensino centrados no aluno, os quais promovem aprendizagens mais profundas e significativas. Os professores, principalmente em fase inicial de carreira, devem realizar formação específica para a sua implementação, devido às elevadas exigências na organização e gestão das atividades. 
Instructional models in Sport:

The student's perspective: Research

in the scope of the professional internship

\section{in Physical Education}

\section{ABSTRACT}

This study examined the representation of students about their experiences in Physical Education classes both within teacher-centered (Direct Instruction Model) and student-centered instructional models (Peer teaching, Cooperative Learning and Sport Education). A trainee teacher and twenty-five 10th grade students (13 females and 12 males) participated in the study. Data collection was comprised of semi-structured focus group interviews. Thematic analysis and inductive procedures were used to build an in-depth understanding of the phenomenon under research. This study reinforced the importance of applying student-centered approaches for teaching physical education if deeper and meaningful learning is to be achieved. Due to the high organisational and instructional demands posed to teachers while implementing student-centred approaches, it is critical that practitioners, particularly those in initial stages of their careers, participate in explicit training of models-based practice.

KEY-WORDS:

Teaching Models. Physical Education.

Professional Internship
Entre modelos de ensino mais centrados no professor e aqueles que concedem mais espaço à descoberta e à iniciativa dos alunos, isto é modelos centrados nos alunos, "há que encontrar o justo equilíbrio entre as necessidades de direcção e apoio e as necessidades de exercitar a autonomia, de modo a criar as condições favoráveis para uma vinculação duradoura à prática desportiva" (13).

No modelo de instrução direta (MID), são privilegiadas as estratégias instrucionais de caráter explícito e formal, sendo a monitorização e controlo estreito das atividades pelo professor a nota dominante ${ }^{(12)}$. Por sua vez, no modelo de ensino com pares (MEP), os alunos trabalham em grupos de dois, sendo atribuída a um dos alunos a função de "professor" e ao outro de "aluno" (14). Tem como principais vantagens, um elevado envolvimento na tarefa, grande quantidade de oportunidades de resposta motora, de correção dos erros e de ajuda e encorajamento ${ }^{(14)}$. 0 modelo de aprendizagem cooperativa (MAC), assenta na prática em grupos acima de dois elementos e visa a mútua ajuda e partilha de responsabilidades ${ }^{(14)}$. Este modelo contribui particularmente para o desenvolvimento das competências pessoais e sociais pela valorização das componentes cognitivas e sociais, seja no contexto escolar ou desportivo ${ }^{(7)}$. 0 modelo de educação desportiva (MED) é específico da Educação Física (EF) e colhe as ideias do MAC, com acentuação da educação lúdica nas orientações curriculares da EF. 0 modelo apresenta como principais caraterísticas a época desportiva, a afiliação, a competição formal, a manutenção de registos estatísticos, a festividade e o evento culminante ${ }^{(17)}$. A preocupação do MED é que as atividades desportivas sejam autênticas e tenham elevado significado e valor para os alunos, inspiradoras da prática desportiva a médio e longo prazo ${ }^{(11)}$. Com a aplicação deste modelo, que oferece as mesmas oportunidades de prática a todos os alunos, independentemente do género e do nível de desempenho de cada jovem, são criadas condições para que se tornem desportivamente competentes, cultos e entusiastas ${ }^{(17)}$.

Rink ${ }^{(16)}$ salienta que não há nenhum modelo que seja adequado a todos os envolvimentos de aprendizagem e que existem questões cruciais que o professor deve ter em consideração, no sentido de utilizar os modelos de ensino que melhor servem os problemas ditados pela sua prática docente. Metzler ${ }^{(14)}$ advoga que ao longo dos anos foi realizada uma comparação abusiva entre modelos de ensino, sem considerar os processos da sua implementação, nem sequer o impacto dos mesmos sobre os discentes, o que, consequentemente, conduziu a generalizações descontextualizadas do processo de ensino.

0 presente estudo tem como objetivo examinar o modo como os alunos representam o significado e preferência atribuída a quatro modelos de ensino durante aulas de EF. Com este propósito foram desenhadas três questões de partida que procuraram ajudar a compreender a perceção dos alunos face aos [i] aos modelos de ensino utilizados e às estratégias adotadas pela professora; [ii] ao modo como se envolveram nas atividades e aos momentos em que sentiram mais interessados e participativos; [iii] aos processos que lhes proporcionaram aprendizagens mais significativas. 


\section{MATERIAL E MÉTODO}

PARTICIPANTES

Participaram no presente estudo, realizado no ano letivo de 2014/2015, os vinte e cinco alunos (13 do sexo feminino e 12 do sexo masculino) que integravam uma turma de 10 o ano de uma escola da zona norte de Portugal e a professara da turma, estudante-estagiária do Mestrado em Educação Física, e simultaneamente investigadora. Enquanto 10 alunos praticavam uma modalidade desportiva, no passado a prática desportiva foi extensiva a 18 alunos. Os procedimentos éticos adotados no presente estudo foram aprovados pela Comissão de Ética da Faculdade de Desporto da Universidade do Porto. Apesar de estar a ser desenvolvido um estudo de investigação com a turma, foi-lhe garantida a possibilidade de recusar participar na entrevista de grupo focal, sem qualquer tipo de consequências, tendo sido a sua participação voluntária. Face à idade dos alunos, foi entregue a cada Encarregado de Educação um pedido de autorização para a participação do seu educando e recolha de imagens para fins pedagógicos, tendo todos autorizado a mesma.

RECOLHA E ANÁLISE DE DADOS

Neste estudo foram utilizadas entrevistas de grupo focais aplicadas pela professora aos alunos. Estas foram aplicadas para promover, aos alunos, oportunidades de discussão e colaboração ${ }^{(15)}$. Uma vez que as entrevistas eram semiestruturadas, permitiram a criação, pela investigadora, de um guião de perguntas abertas ${ }^{(5)}$. 0 guião foi dividido em três blocos temáticos: (1) Legitimação da entrevista: Informar acerca do objetivo da entrevista; Valorizar o contributo do aluno; Garantir a confidencialidade e anonimato das respostas; (2) Revisão do percurso desenvolvimento ao longo do ano; (3) conhecer a opinião dos alunos sobre a preferência pelos diferentes modelos de ensino relativamente ao incentivo para a participação e aprendizagem; atribuição de responsabilidades e autonomia no desenvolvimento das tarefas; e desenvolvimento do gosto pela prática desportiva. Em cada entrevista de grupo focal participaram 5 alunos para além da professora, o que possibilitou uma participação ativa e uma discussão profunda dos aspetos relevantes ${ }^{(18 ; 10)}$. 0 material recoIhido foi transcrito e analisado e sofreu um processo de análise indutiva, a qual inclui uma análise inicial, seguida de uma análise focada e, posteriormente, de uma análise teórica ${ }^{(4)}$

\section{RESULTADOS E DISCUSSÃO}

MODELO DE INSTRUÇÃO DIRETA

As estratégias de ensino mais explícitas e formais adotadas pela professora no início do ano (nas unidades de Voleibol e Ginástica Artística) foram percebidas pelos alunos como uma necessidade da mesma controlar a turma, pelo "perigo" à proximidade das suas ida- des e inexperiência de ensino. Os feedbacks constantes que a professora dava, e que caraterizam o MID, não foram considerados como um aspeto negativo. Pelo contrário, os alunos sentiram-se apoiados e ajudados na travessia das suas dificuldades:

"No início do ano... não brincava. E acho que é um bocado por ser estagiária, como é mais nova não se quer mostrar fraca (...) para não nos dar hipótese de abusar (...) antes era mais "fazem isto e acabou" E5G1;"Prefiro e quero que a stora me dê conselhos, porque quando eu não estou a fazer uma coisa bem, eu quero que a stora diga como é que eu tenho que fazer (...)" E4G2.

As habilidades motoras eram explicadas e demonstradas pela professora para rentabilizar o tempo disponível e proporcionar aos alunos a visualização de execuções corretas. Ademais, a proatividade da professora, principalmente para iniciar as atividades, foi percebida como crucial para aumentar os níveis de participação e envolvimento dos alunos.

"A stora ao explicar e a fazer por si as posições também ajuda bastante (...) Se fosse o aluno (...) não tinha uma ideia tão bem da posição como a stora" E3G4. “(...) Nós enrolamos ali e a stora vai direta ao assunto (...) a base era com a stora e aprender era com a professora." E1G1. "A stora tem de arrancar para nós conseguirmos andar" E5G1.

Os alunos valorizaram esta abordagem diretiva da professora, pois se por um lado esta precisava de tempo para sentir controle sobre a turma ${ }^{(8)}$ por outro, eles precisavam de tempo para aprenderem a trabalhar em conjunto ${ }^{(9)}$. No entanto, é importante ressalvar que o uso de estratégias diretivas, durante um tempo muito prolongado, pode ter efeitos contrários aos desejados, conforme foi percebido pelos alunos:

Isso, de estar sempre em cima, também não é bom (...) é bom nós termos um bocado o nosso espaço para pormos as nossas ideias em prática e não apenas aquilo que o professo manda" E2G2.

MODELO DE ENSINO ENTRE PARES

Nas unidades de ensino de Voleibol e de Andebol, os alunos foram particularmente incentivados à colaboração mútua no desenvolvimento das tarefas através do ensino entre pares. Os alunos valorizaram, sobremaneira, serem ajudados genuinamente pelos colegas com quem estavam a trabalhar:

"E a stora disse-me: "vê se os metes a fazer isto" (...) antes as storas nunca faziam isso comigo e tambem me levou a subir ainda mais a minha autoestima." E3G2. "Acho que foi a modalidade que a stora obrigou mais os que sabiam (..) a ajudar os outros, dizia sempre "ah, o que tu já sabes, agora vais ensinar a este" (...) eles ajudavam-me e ensinavam-me" E3G1. 
Bayraktar (1) e Cardoso ${ }^{(3)}$ nos seus estudos constataram que os alunos revelaram satisfação pela entreajuda e possibilidade de ensinar os colegas, sentindo-se úteis. Não obstante, no nosso estudo, os alunos reconheceram o valor da ajuda e apoio aos colegas, referiram a necessidade de existir equilíbrio entre o tempo de ajuda e o tempo disponível para praticar com alunos do mesmo nível de desempenho motor.

"Não eramos muito unidos e qualquer coisa era apontar logo o dedo (...) mas isso foi só no início." E1G1.“(...) o aluno bom pode querer jogar com pessoas que the dê luta (...) Isso é bom numas aulas, mas se for constantemente não, mas se alternar assim sim" E3G4.

MODELO DE APRENDIZAGEM COOPERATIVA (GINÁSTICA ACROBÁTICA)

As aprendizagens que os alunos realizaram nesta unidade de ensino parecem ter sido fortemente influenciadas pelo trabalho colaborativo que foi alargado a toda a turma. De facto, os alunos evidenciaram um crescente sentido de responsabilidade, compromisso, satisfação e autonomia na realização do trabalho em conjunto:

"Foi a melhor coisa para mim. Nós pudemos fazer, até, a coreografia (...) Possibilitou que usássemos a nossa criatividade" E2G3; "(...) tínhamos que nos esforçar (...) porque se nós não fizéssemos não eramos só nós que nos estávamos a arruinar, mas sim o grupo inteiro (...)" E1G1.

Para além disso, a autonomia atribuída aos grupos para a construção da rotina, alvo de posterior avaliação, aumentou o significado dos resultados obtidos, porquanto foi maioritariamente conseguido pelo seu esforço.

".... stora via o nosso esquema mas o esquema era nosso, a stora ajudava mas o esquema era nosso, nós tivemos a responsabilidade de o trabalhar e de o apresentar (...) e tivemos aulas extra e tudo." E3G1.

Estes resultados evidenciam o valor da aprendizagem cooperativa no incremento da autonomia e da capacidade para lidar ${ }^{(9)}$ bem como promover a participação ativa no grupo aceitando as suas responsabilidades ${ }^{(6)}$.

MODELO DE EDUCAÇÃO DESPORTIVA (VOLEIBOL E ANDEBOL)

0 papel assumido pelos alunos que desempenharam a função de treinador nas equipas, aumentou a afiliação ao grupo e o sentido de cooperação de todos os alunos:

"Ajudou muita gente (...) senti que as minhas dificuldades não eram uma barreira à prática (...) toda a gente participava, ninguém ficava de parte" E1G3.
A crescente motivação para a aprendizagem através do MED foi muito vincada pelos alunos, tendo a competição surgido como o principal fator para a autossuperação e superação das equipas adversárias.

"No torneio, era aquela coisa de 'ah, não sei quê, vamos ser os melhores!' Se calhar, nos torneios acaba por haver muito mais esforço e muita mais dedicação por parte das pessoas" E2G2

No entanto, e apesar da competição ser vista por todos como um incentivo à realização das aulas com mais empenho e dedicação, os alunos reconheceram que nem sempre foi fácil lidar com a competição, em resultado do 'encontro' das diferentes personalidades existentes na turma.

"Os torneios, apesar de terem sido todos muito bons, não foram fáceis porque havia a disputa, a competição..." E3G1.

Por forma a que as atividades desportivas fossem autênticas, tivessem maior significado e valor para os discentes e fossem suficientemente inspiradoras e desafiantes, a professora proporcionou experiências que se assemelhassem ao desporto federado, tendo sido encaradas pelos alunos de forma entusiasta:

“(...) Como a stora viu que nós eramos umas pessoas fixolas, começou a libertar-se mais e usa técnicas mais engraçadas. Por exemplo no início do ano não mandou fazer os prémios em casa mas a meio já mandou ..." E5G1. "Eu adoro é o grito no final de cada aula. Isso incentiva, faz com que ganhemos uma união. (...) Somos uma turma que ... falo por mim, é muito unida graças às aulas de física (...) não é assim: «a aula já acabou, podem ir embora». Não, «a aula acabou, fazemos o grito e depois podem ir embora»" E1G4.

Bennett e Hastie (2) referem que, segundo os alunos, a afiliação às equipas e às diversas competições formais são as caraterísticas mais atrativas, levando à realização de um trabalho com mais dedicação e encarado de forma mais séria.

\section{CONCLUSÕES}

Os alunos reconheceram a importância da vivência de experiências de aprendizagem a partir de diferentes modelos de ensino. Não obstante, foi nos dois modelos de ensino mais centrados no aluno (MAC e o MED) que perceberam terem usufruído de mais oportunidades para se tornarem autónomos, desenvolverem a responsabilidade pessoal e social e alcançarem aprendizagens mais significativas. Mormente, no MAC por definirem as suas próprias metas e criarem rotinas com que se identificavam, e no MED, pelo elevado desenvolvimento do sentido de pertença, fruto do trabalho permanente em equipa. 


\section{AUTORES}

3. Cardoso FJ (2014). Gimnocerco: Um exemplo de empoderamento, de excelência desportiva e de desenvolvimento de competências de vida. Porto: Fernando Cardoso. Dissertação de Doutoramento apresentada a FADEUP.

4. Charmaz K (2006). Constructing grounded theory. A practical guide through qualitative analysis. London: Sage. 5. Cohen L, Manion L, Morrison K (2011). Research methods in education ( $7^{\text {th }}$ edition). London: Routledge. 6. Dyson B, Strachan K (2004). The ecology of cooperative learning in a highschool physical education proramme Waik to Joun of Education, 10,117-1397. Fonseca U, Mescuta I (2012). Modelo de educaca educação desportiva: 0 refundar do valor pedagógico e social do desporto na escola. In J. Moreira, A. Ferreira \& A. Mendes (Org.), Rumos pedagógicos da educação física em Portugal. Santo Tirso: De facto editores.

8. Greenockle KM, Purvis GJ (1995). Redesigning a secondary school wellness unit using the criticel thinking model. Journal of Physical Education Recreation \& Dance, 66 (6), 49-52.

9. Johnson DW, Johnson RT (1999). Making cooperative learning work. Theory into practice, 38(2), 67-73. 10. Krueger RA, Casey MA (2009). Focus group: a practical guide for applied research. (4th ed). London: Sage. 11. Mesquita I (2012). Fundar o lugar do desporto na escola através do modelo de educação desportiva. In I. Mesquita \& J. Bento (Eds.), Professor de Educação Física: Fundar e dignificar a profissão (pp. 177-206). Belo Horizonte: Casa da Educação Física.

2. Mesquita I, Graça A (2006). Modelos de ensino dos jogos desportivos. In G. Tani, J. O. Bento \& R. D. d. S. Petersen (Eds.), Pedagogia do desporto (pp. 269-283). Rio de Janeiro: Guanabara Koogan.

13. Mesquita I, Graça A (2011). Modelos instrucionais no ensino do desporto. In A. Rosado \& I. Mesquita (Eds). Pedagogia do Desporto (pp. 39-68). Cruz Ouebrada: Edições FMH.

14. Metzler MW (2000). Instructional models for physical education. Boston: Allyn and Bacon.

\section{RESUMO} tes de crenças sobre o conteúdo.
Valmor Ramos

Jeferson Souza

Vinícius Brasil

Ana Flávia Backes ${ }^{1}$

Filipy Kuhn ${ }^{1}$

Carine Collet ${ }^{1}$

Universidade Federal de Santa Catarina, Florianópolis, SC, Brasil

As crenças sobre search. London: Sage.

16. Rink JE (2001). Investigating the assumptions of pedagogy. Journal of teaching in physical education, 20(2), 112-128

17. Siedentop D (Ed.). (1994). Sport education: QualiHuman Kinetics.

8. Wibeck V, Abrandt Dahlgren M, Oberg G (2007). earning in focus group: an analytical dimension for enhancing focus group research. Qualitative research, 7(2), 249-267.

https://doi.org/10.5628/rpcd.17.S1A.115 os conteúdos de ensino

dos esportes na formação

\section{inicial em Educação Física}

PALAVRAS CHAVE:

Crenças. Ensino. Conteúdos.

Esporte. Formação Inicial.

O objetivo do estudo foi analisar as crenças sobre os conteúdos de ensino dos esportes de graduandos ingressantes do curso de Bacharelado em Educação Física, em uma universidade pública do Estado de Santa Catarina, Brasil. Adotou-se uma abordagem de pesquisa qualitativa, descritiva e interpretativa, a partir de um estudo transversal com procedimentos de casos múltiplos. Para obtenção dos dados, foram aplicados junto a oito graduandos, entrevista estruturada e semiestruturada, observação sistemática e procedimentos de estimulação de memória. A análise dos dados foi realizada por meio da técnica de análise de conteúdo. Os resultados indicaram que os graduandos possuem crenças que privilegiam o ensino de conteúdos motores ou habilidades técnicas, bem como a organização curricular dos conteúdos em função da complexidade técnica e da variação da execução motora. As experiências de prática e observação de professores e treinadores foram as principais fon-

Correspondência: Valmor Ramos (valmor.ramos@udesc.br).

115 - RPCD 17 (S1.A): 115-122 